\title{
Modelling Residential Heat Demand Supplied by a Local Smart Electric Thermal Storage System
}

\author{
Zane Broka, Jevgenijs Kozadajevs, Antans Sauhats \\ Institute of Power Engineering \\ Riga Technical University \\ Riga, Latvia \\ zane.broka@rtu.lv, jevgenijs.kozadajevs@rtu.lv, \\ sauhatas@eef.rtu.lv
}

\author{
Donal P. Finn, William J.N. Turner \\ Energy Institute \\ University College Dublin \\ Belfield, Dublin 4, Ireland \\ donal.finn@ucd.ie,will.turner@ucd.ie
}

\begin{abstract}
This paper presents an inverse modelling approach for deriving equivalent thermal parameters of buildings. A simplified thermal network based on electrical analogy was developed to replicate building thermal dynamics and model residential heat demand. The study employs data driven blackbox modelling based on the measured indoor and outdoor temperature. To validate the proposed method, virtual and physical experiments were conducted and performance of the simplified thermal network model was compared to two more complex RC models and measurements in an existing building. The simplified model was able to replicate the thermal dynamics of the complex models and the building with a high accuracy at the same conditions under which model parameters were estimated implying that for accurate modelling a large amount of experimental data obtained under various conditions is required. Such data will be gathered in the upcoming studies from 50 buildings in Latvia. The obtained data will then be used to model the aggregate heating demand at a national scale for assessment of the impact of smart electric thermal storage appliances on the overall power system.
\end{abstract}

Keywords-inverse modelling; RC model; thermal network, thermal storage

\section{INTRODUCTION}

Dissemination of intermittent renewable energy sources (RES) such as wind, wave and solar power presents new challenges for the power systems. In order to reduce the curtailment of renewables and efficiently accommodate the distributed and variable RES across the power system, energy storage has become a necessity. Various forms of energy storage include mechanical energy storage (hydropower, compressed air, flywheel), electrochemical batteries, power to gas storage, electric and magnetic energy storage (capacitors and supercapacitors, superconducting materials) and thermal energy storage.

While there are mature and long-known technologies for large-scale energy storage such as pumped-storage hydropower, which is the mostly used storage option in the power sector worldwide, many efforts are devoted to development of small-scale energy storage primarily for use in the residential sector. One of such technologies is smart electric thermal storage with household appliances for space heating and hot water heating [1]. It is a sensible heat storage

This work is part of the RealValue project. This project has received funding from the European Union's Horizon 2020 research and innovation programme under grant agreement No 646116. system [2] which consumes electricity and is able to store it in the form of thermal energy for a long time to be used later just when it is needed. Thus the power demand of the heating system is decoupled from the time of thermal energy end-use by the domestic customer.

Electric thermal storage heaters have been in use for decades especially in countries where two-tariff electricity pricing is applied to households. The conventional thermal storage heaters had a limited controllability due to relatively low heat retention rate. However, for the newest generation of smart electric thermal storage (SETS) system, the heat retention rate is significantly improved and the recent advances of information and communication technologies have allowed a significant technological development of the storage heaters. SETS devices are now equipped with smart control at the aggregate electric power system level while ensuring that individual household space and water heating end-use requirements are maintained [1]. It allows to decouple the electricity demand from the expected heat output and deliver electricity to the SETS virtually at any time while consuming the heat at any other time when it is needed. Consequently, the whole electricity supply chain, including generation, transmission, distribution and consumption, can potentially benefit from SETS

SETS can provide overall societal benefits such as cost savings to the customers and RES curtailment reduction, whereas the aggregated load can offer a number of services to the power system such as demand shifting and demand response, ancillary services (frequency response, reserves provision), congestion management and deferral of capital investments into the network.

It is estimated that by retrofitting all existing night storage heaters in the European Union, SETS could introduce a controllable load of $55 \mathrm{GW}$ ( $37 \mathrm{GW}$ for all traditional night storage heaters and $18 \mathrm{GW}$ for hot water) and, consequently, save 7.4 TWh of heating energy per year and avoid 3 million tons of $\mathrm{CO}_{2}$ emissions per year compared to conventional storage heaters [3].

While the SETS technology and appliances are in place already [1], the power systems are not yet in a position to integrate them and there are various ongoing studies on how to 
facilitate this process. One of the problems to be solved includes co-optimisation of the electricity system scheduling together with requirements of the electric heating demand [2]. The modelling and optimisation environment for electrical power systems should endogenously represent the local smallscale thermal storage devices, including their technical characteristics and thermal energy end-use requirements.

To assess the potential cost savings to the customers when using SETS with dynamic pricing under conditions of a liberalised electricity market, the variable electricity prices need to be considered with appropriate temporal resolution (e.g., hourly resolution for the Nord Pool day-ahead market prices). Consequently, thermal energy end-use should also be modelled with an hourly resolution.

This paper is focused on modelling the residential heating energy demand. We propose an approach based on physical experiments and virtual simulations to obtain the equivalent thermal characteristics of the building which can then be used for modelling the thermodynamics of the building under different weather conditions.

The approach presented in this paper will serve as basis for our further studies involving physical experiments in 50 different buildings in Latvia to derive their thermal characteristics and heating energy requirements. The consumption of individual buildings will then be scaled to a national aggregate level. The aggregated electric load of local small-scale thermal storage will be integrated into the overall power system models to assess the impact of storage devices on power system planning, unit commitment and dispatch of energy and reserves, distribution network congestion, power system reliability etc. While that will be presented in our future publications, this paper is focused solely on modelling of heating energy demand in buildings.

SETS technology and equipment is presented in section II followed by an overview of heat demand modelling approaches in section III with a focus on the experimental approach used in our study. Next, the results of virtual simulations and physical experiments are provided by comparing the simplified model with two complex models in section IV. Finally, conclusions are drawn.

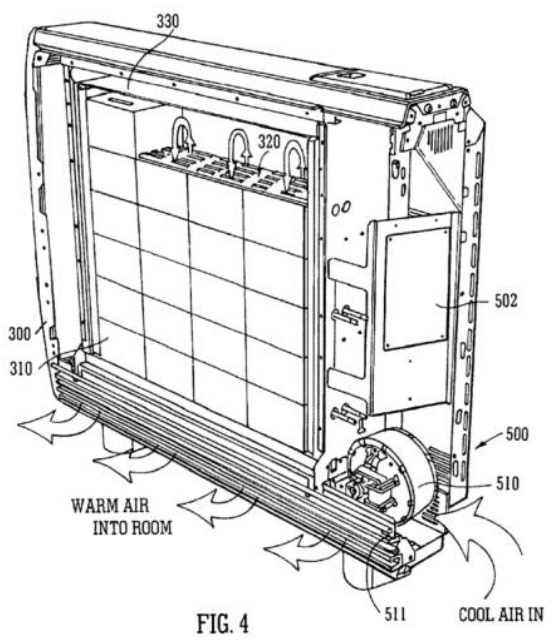

Fig. 1. SETS for space heating [1]

\section{Smart Electric Thermal Storage TechnOlogy}

SETS is a decentralised space heating and hot water system with energy storage and up to $20 \%$ efficiency gains compared to traditional night storage heaters [1]. It consists of electric space heating radiators with an insulated thermal mass for storing heat (Fig. 1) and a hot water cylinder (Fig. 2).

SETS space heaters contain a highly insulated solid thermal energy storage core of bricks which enables the conversion of electrical energy into thermal energy for use at a later time [1]. The heat is released into the room by radiation and convection. Modern dynamic electric storage heaters are equipped with a fan which blows warm air from the core of the heater into the room. This allows for a more precise heat distribution control as compared to conventional static storage heaters without a fan blower [2].

Recent developments of material and electronic control technologies have enabled storage heaters to provide the householder with time and temperature control comparable with direct electric heating technologies. Additionally these devices can be managed remotely so that they can be charged flexibly at a time when it best suits the electricity system without jeopardising householder comfort [1].

The application range of dynamic electric storage heaters with a fan is typically $2-7 \mathrm{~kW}$ with a storage capacity of 16 $56 \mathrm{kWh}$ per charge cycle. The application range of static electric storage heaters is typically $0.75-3 \mathrm{~kW}$ with a storage capacity of $8-24 \mathrm{kWh}$. The maximum core temperature is about $700{ }^{\circ} \mathrm{C}[2]$.

SETS water cylinders use the same basic principle, except that the energy is stored in water rather than a solid medium. Both systems share the same communications and control architecture and can therefore be managed in a unified manner [3].

SETS includes advanced electronic command and control capabilities such as an automated input control with adaptive learning function to determine how much heat will be needed on a particular day, while accounting for prevailing weather conditions.

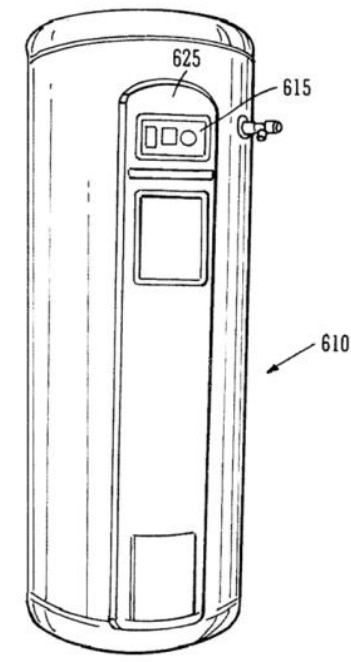

Fig. 2. SETS for hot water heating [1] 
This daily energy requirement is calculated using an algorithm based on the residual stored energy, the rate of change in room temperature after the evening heating period, as well as user-programmed heating requirements. SETS uses ICT to enable flexible tariff regimes, to support integration of renewable energy resources at any time, allowing time of use tariff schemes to be integrated in the operation of SETS [3].

SETS facilitates the decoupling of energy production from energy consumption, so that renewable energy can be converted into heat and offers control over when this heat is released. This allows low carbon space heating and hot water to be deployed when the end user desires it [3].

\section{HeAt DEMAND Modelling}

\section{A. Review of Modelling Approaches}

Mathematical models for simulating building energy systems and consumption can be of theoretical and experimental type [4]. Theoretical models are described by mathematical equations derived from physical laws, whereas experimental models are devised empirically by measuring input and output signals of the system and evaluating the system's response.

Modelling structure for any energy system consists of three main blocks: input variables, output variables and the system itself (Fig. 3) [4]. During the modelling we need to determine one of the three building blocks when adequate information about the other two blocks is available. Consequently, the energy models are classified as white-box, black-box or greybox models.

White-box models are highly accurate and use forward approach to predict the output variables based on a detailed structure and parameters of the model subjected to specific input variables [4]. To employ this approach, it is assumed that all the thermal and geometric building characteristics are wellknown, which is usually the case for building design but is much difficult and expensive to obtain for already existing buildings [5].

Black-box models use a data driven approach to develop the model based on the knowledge of the input and output data acquired through experiments [4]. Black-box approaches often employ statistical or machine learning to derive a prediction model from a database, e.g., actual or forecasted energy consumption of a building [5]. When experimental data us obtained within the building, it is done either in an intrusive or a non-intrusive manner [4].

Grey-box or hybrid modelling involves formulating a physical model and identifying important and aggregated parameters and characteristics by statistical analysis which requires a high level of expertise [4]. Whereas black-box models don't need a detailed description of the building geometry, they require a large amount of training data over an exhaustive period of time. In contrast, for grey-box models a small amount of data for training is necessary with a rough description of the building geometry. As opposite to white-box and grey-box models the results of which can be interpreted in physical terms, black-box model results can be difficult to interpret in physical terms [5], [6]. However, automatic parameter estimation using a black-box model has a significant advantage over white-box models having a small setup cost and little computational effort [7].

In our study, we employ an experimental black-box modelling approach by using the outside temperature and heating consumption of the building as input data and the room temperature as output data. Based on this data, thermal parameters of the building are obtained which are then used to estimate the heating consumption under different weather conditions at various time scales, e.g., hourly, daily, weekly or yearly.

This approach is also referred to as the inverse problem whereby the physical characteristics of a building are acquired given the actual performance data [8]. That is a classical problem known as parameter estimation or system identification problem [9]. The building is considered as a black box the characteristics of which are derived from temperature measurements and energy consumption data [8]. Mathematically, the thermodynamics of the building can be described by a differential equation with unknown parameters. Using the measured values of input and output, the best or optimal estimate of these parameters is obtained.

A similar approach is implemented in [10], where a model of the space heating and cooling load is proposed to study its behaviour during cold load pickup after a power outage. The model is able to capture the thermal characteristics of a house at a thermostat without modelling all the details of the house. Since a detailed simulation model for the house thermodynamics used traditionally for the thermal design studies of the building is not practical for modelling a systemlevel heating load, the authors have minimised the data and computation requirements while making a maximum use of the available data. Yet, the model is accurate enough for the study of cold load pickup. The parameters for the model can be obtained very easily through simple measurements: the authors use only the thermal characteristics as observed at the thermostat, i.e., the room temperature. A simple model is derived based on the assumption that the thermostat condenses building thermal characteristics (including the effects of weather conditions and resident lifestyle) into two variableson-duration for heating and off-duration for cooling between to setpoints of the thermostat. The parameters of the model are

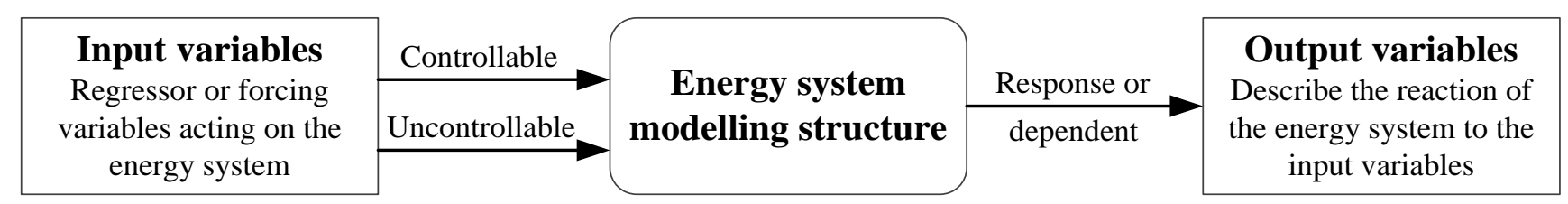

Fig. 3. Modelling structure of a building energy system [4] 
obtained through simple experiments by turning the heater off and on for a definite time and measuring the temperature at the thermostat. Finally, after additional simplifications and approximations all the dynamic characteristics of the house are summarized into a single parameter (harmonic constant), which is independent of weather and internal heat source. To find this constant, only the on/off-durations are required.

The objective of [10] has been to provide a quantitative method to predict the magnitude and duration of the overload following an outage. We suggest that a similar approach can be used to model the various effects on the power system of dissemination of a large amount of smart electric thermal storage appliances.

\section{B. Building Thermal Models Based on Electrical Analogy}

For modelling thermodynamics of buildings, RC-diagrams are often used based on electrical analogy where each element of the building can be represented with resistors and capacitors as lumped parameters [11]-[15]. Such thermal network models have advantages of simplicity, transparency and low computational effort [12].

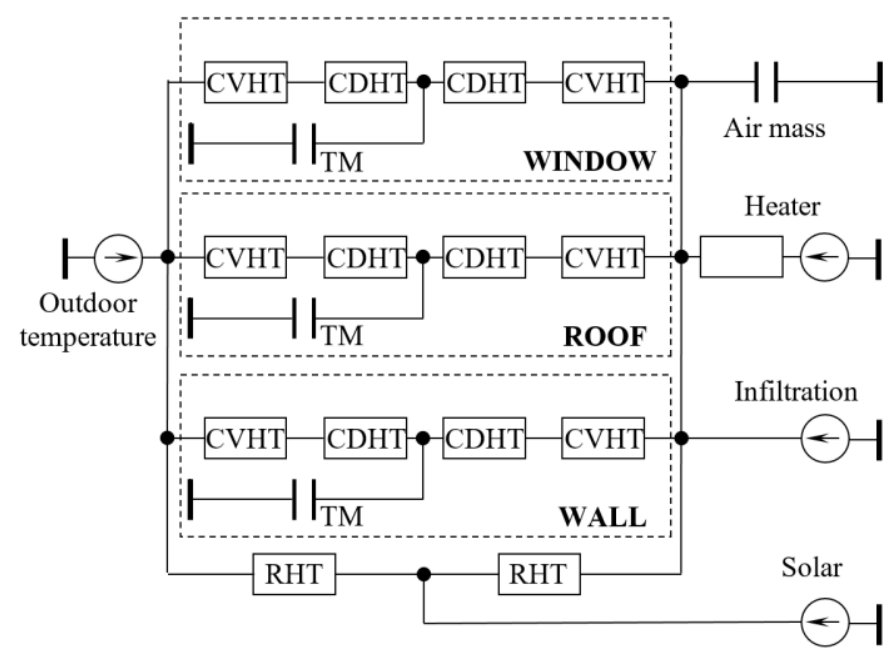

Fig. 4. The complex thermal network used for virtual experiments (CVHTconvective heat transfer, CDHT-conductive heat transfer, RHT-radiative heat transfer, TM-thermal mass)

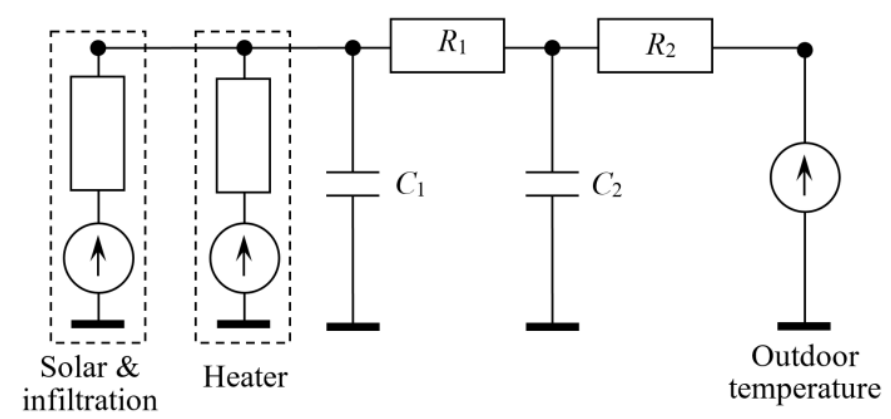

Fig. 5. The simplified thermal network used for inverse modelling
Theoretically, the simplest network might consist of one resistance and one capacitor [8]. However, this is practically and physically unrealistic, therefore usually more elements are used. E.g., [12]-[14] use second-order models that describe construction elements by three resistances and two capacitances. In [14], this reduced-order model is devised from a $20^{\text {th }}$-order model through nonlinear constrained optimisation and is given preference over an even simpler first-order model since the latter showed considerable performance differences from the high-order model unlike the second-order model. This approach is further improved in [12] by using a multi-objective function search algorithm and reporting a large number of results for various construction elements.

In our study, we use a thermal network model as presented in Fig. 4. Since we employ inverse modelling, we need to use equivalent thermal parameters to obtain a simple network [8]. Therefore we have devised a simplified model (Fig. 5) based on the complex one. The complex model is built in Simscape which allows to easily create models of physical systems and perform simulations on them using MATLAB Simulink. The output data of simulations are then used for parameter estimation of the simplified model. We should note that, at this stage, we have assumed there are no heat losses and gains from infiltration or solar gains. However, later on as we develop our study, these gains will also be accounted for.

Additionally, in section IV, we have compared the capability of the inverse modelling approach to replicate performance of an even more complex thermal network calibrated with an EnergyPlus building model.

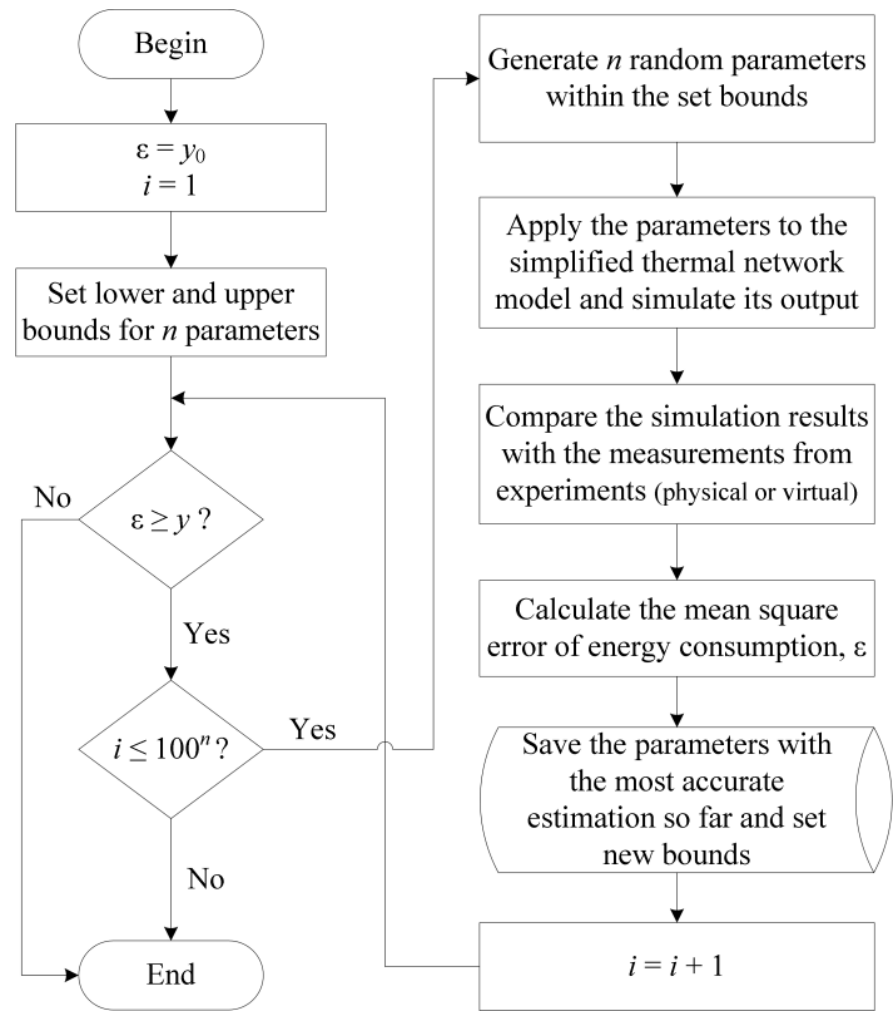

Fig. 6. Flowchart for parameter estimation of the simplified thermal network 


\section{Model Parameter Estimation}

Equivalent thermal parameters $R_{1}, R_{2}, C_{1}$ and $C_{2}$ (Fig. 5) were estimated according to the algorithm shown in Fig. 6. Model parameters were generated randomly employing Monte Carlo sampling and then applied to the simplified thermal network for simulation. The output of the model (energy consumption) was compared with measurements of virtual or physical experiments using mean square error. The sampling was repeated for $100^{n}$ times, where $n=4$ is the number of unknown parameters. The parameters which provided the most accurate performance of the model were saved. This approach comprises a partial enumeration with a high accuracy thanks to the Monte Carlo random sampling, which allows to select a result close to the global minimum avoiding local minima. The model with its tuned parameters can then be used for building heating energy demand modelling at the individual and aggregate level.

\section{RESULTS AND DISCUSSION}

In order to estimate building parameters (Fig. 5), we performed several virtual and physical experiments employing the simplified model to simulate thermal dynamics of the building in subsection A. Besides that, we also compared performance of the simplified model with a complex one in subsection B.

\section{A. Employment of the Simplified Model}

\section{1) Virtual Experiments}

For virtual experiments, we selected three types of buildings with the same geometry, but different insulation levels (house 1 having the least insulation and house 3 with the best insulation; all the parameters of buildings are presented in Table I).

We used the complex model (Fig. 4) to simulate the performance of each building (namely, heating energy consumption) under different weather conditions. Using the data of outside temperature, heat energy consumption and room temperature obtained from simulations of the complex model, we then estimated the corresponding thermal parameters for the simplified model of the building.

Fig. 7 illustrates the performance errors of the simplified model for House 1 with estimated parameters at the outside temperature of $0{ }^{\circ} \mathrm{C}$. While there is no energy consumption error at the outside temperature of $0{ }^{\circ} \mathrm{C}$, the accuracy significantly decreases up to error of $9 \%$ at other outside temperatures which were not used for parameter estimation of the model.

Consequently, we expanded the range of experiments for parameter estimation with more outside temperatures, namely: $-10,-5,5$ and $10{ }^{\circ} \mathrm{C}$. Model performance errors with the estimated parameters for House 2 and 3 are presented in Fig. 8 Fig. 10.

As shown in Fig. 8-Fig. 9, energy consumption errors are zero at the outside temperatures which were used for parameter estimation (circle markers). At other temperatures (diamond labels) errors tend to increase for longer simulations of energy consumption (compare Fig. 9 for 72 hours versus Fig. 8 for 48 hours).

TABLE I. BUILDING PARAMETERS FOR VIRTUAL EXPERIMENTS

\begin{tabular}{|c|c|c|c|}
\hline \multirow{2}{*}{ Parameter } & \multicolumn{3}{|c|}{ Building Construction Element } \\
\hline & Walls & Windows & Roof \\
\hline Area $\left(\mathrm{m}^{2}\right)$ & 320 & 6 & 601 \\
\hline Thickness (m) & 0.2 & 0.01 & 0.2 \\
\hline $\begin{array}{l}\text { Convective heat transfer coefficient } \\
\text { with indoor air }\left(\mathrm{W} /\left(\mathrm{m}^{2} \cdot \mathrm{K}\right)\right)\end{array}$ & 24 & 25 & 12 \\
\hline $\begin{array}{l}\text { Convective heat transfer coefficient } \\
\text { with atmosphere }\left(\mathrm{W} /\left(\mathrm{m}^{2} \cdot \mathrm{K}\right)\right)\end{array}$ & 34 & 32 & 38 \\
\hline Specific heat capacity $(\mathrm{J} /(\mathrm{kg} \cdot \mathrm{K}))$ & 835 & 840 & 835 \\
\hline \multicolumn{4}{|l|}{ House 1} \\
\hline Thermal conductivity $(\mathrm{W} /(\mathrm{m} \cdot \mathrm{K}))$ & 0.038 & 0.78 & 0.035 \\
\hline Mass (kg) & 122880 & 162 & 3845 \\
\hline Density $\left(\mathrm{kg} / \mathrm{m}^{3}\right)$ & 1920 & 2700 & 32 \\
\hline \multicolumn{4}{|l|}{ House 2} \\
\hline Thermal conductivity $(\mathrm{W} /(\mathrm{m} \cdot \mathrm{K}))$ & 0.0038 & 0.0078 & 0.0035 \\
\hline Mass (kg) & 122880 & 243 & 7680 \\
\hline Density $\left(\mathrm{kg} / \mathrm{m}^{3}\right)$ & 1920 & 4050 & 64 \\
\hline \multicolumn{4}{|l|}{ House 3} \\
\hline Thermal conductivity $(\mathrm{W} /(\mathrm{m} \cdot \mathrm{K}))$ & 0.0019 & 0.0038 & 0.00185 \\
\hline Mass (kg) & 245760 & 486 & 38450 \\
\hline Density $\left(\mathrm{kg} / \mathrm{m}^{3}\right)$ & 3840 & 8100 & 320 \\
\hline
\end{tabular}

For House 3, errors were zero for energy consumption over 48 hours, while the errors increased for a simulation of 150 hours (Fig. 10).

These errors are mostly due to the delay or advance of the signal representing the thermodynamics of the house in relation to the actual signal (Fig. 11).

\section{2) Physical Experiment}

Additionally, we conducted a physical experiment on a real residential building by measuring its room temperature and the corresponding outside temperature during heating and cooling of the building in winter (i.e., with the heater turned on or off) (Fig. 12). As previously, we used the measured inside temperature and information on the outside temperature to estimate the thermal characteristics of the building. As shown in Fig. 12, the derived model exhibits a high performance accuracy as compared to the experimental data.

Besides the temperature measurements, energy consumption of the building was recorded. Knowing the heating demand of representative individual buildings, we will be able to calculate the aggregated heating load of SETS in our further studies. 


\section{Error, \%}

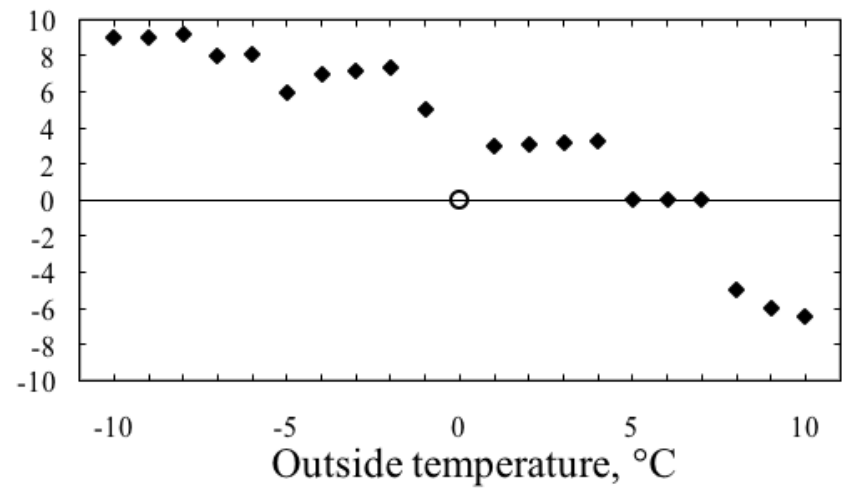

Fig. 7. Energy consumption errors for House 1 at different outside temperatures for model with parameters estimated at the outside temperature of $0{ }^{\circ} \mathrm{C}$ (circle marker)

\section{Error, \%}

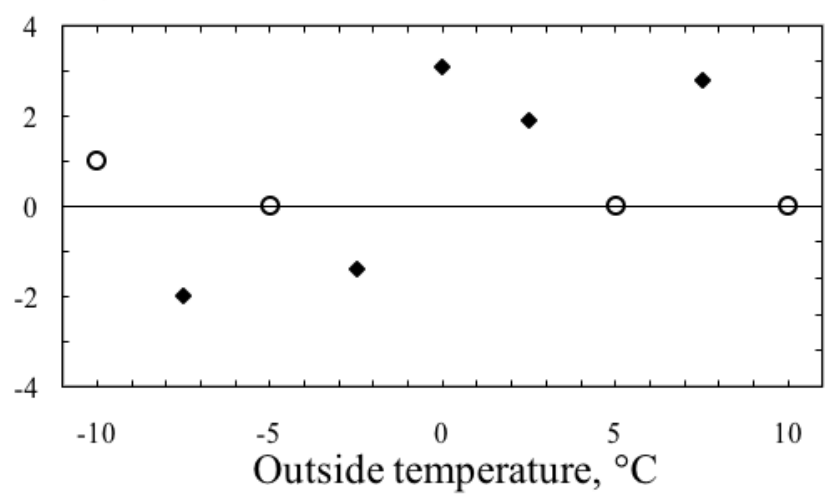

Fig. 9. Energy consumption errors for House 2 over 72 hours at different outside temperatures for model with parameters estimated at the outside temperature of $-10,-5,5$ and $10^{\circ} \mathrm{C}$ (circle markers)

Temperature, ${ }^{\circ} \mathrm{C}$

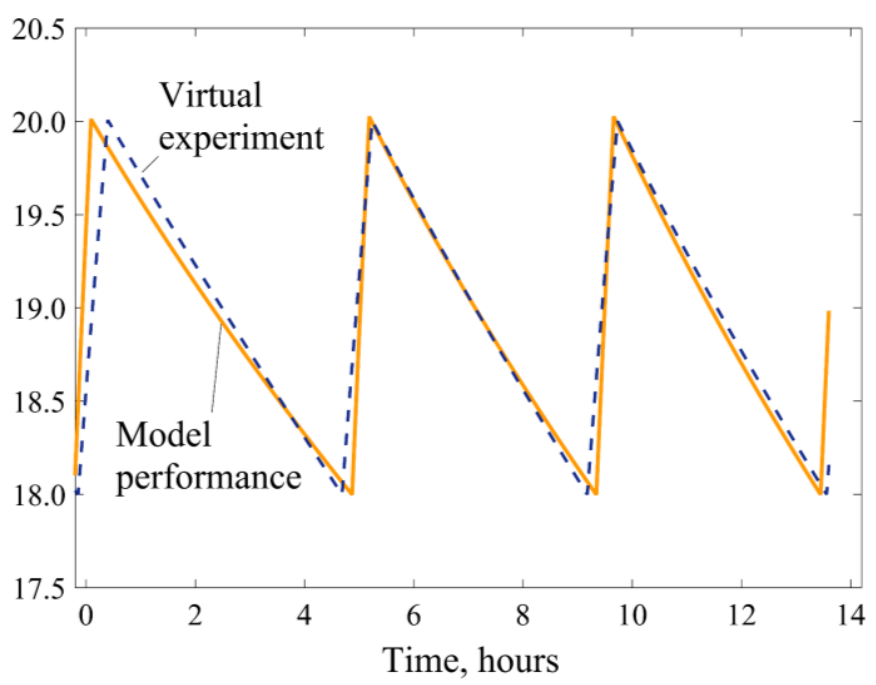

Fig. 11. Virtual experimental data of room temperature and the corresponding model performance as estimated for a constant outside temperature of $0{ }^{\circ} \mathrm{C}$

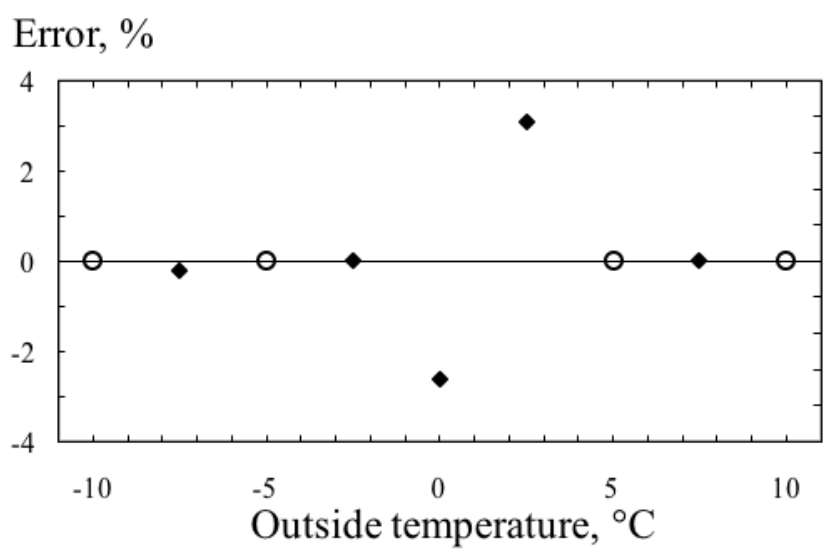

Fig. 8. Energy consumption errors for House 2 over 48 hours at different outside temperatures for model with parameters estimated at the outside temperature of $-10,-5,5$ and $10^{\circ} \mathrm{C}$ (circle markers)

Error, \%

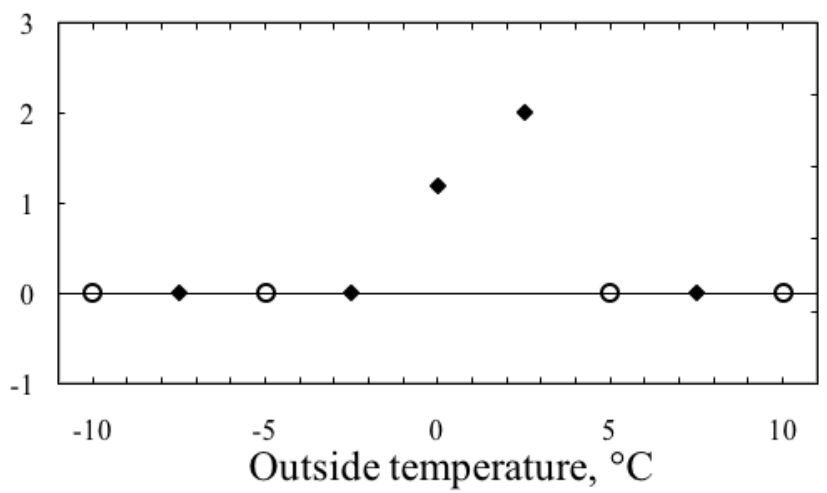

Fig. 10. Energy consumption errors for House 3 over 150 hours at different outside temperatures for model with parameters estimated at the outside temperature of $-10,-5,5$ and $10^{\circ} \mathrm{C}$ (circle markers)

\section{Temperature, ${ }^{\circ} \mathrm{C}$}

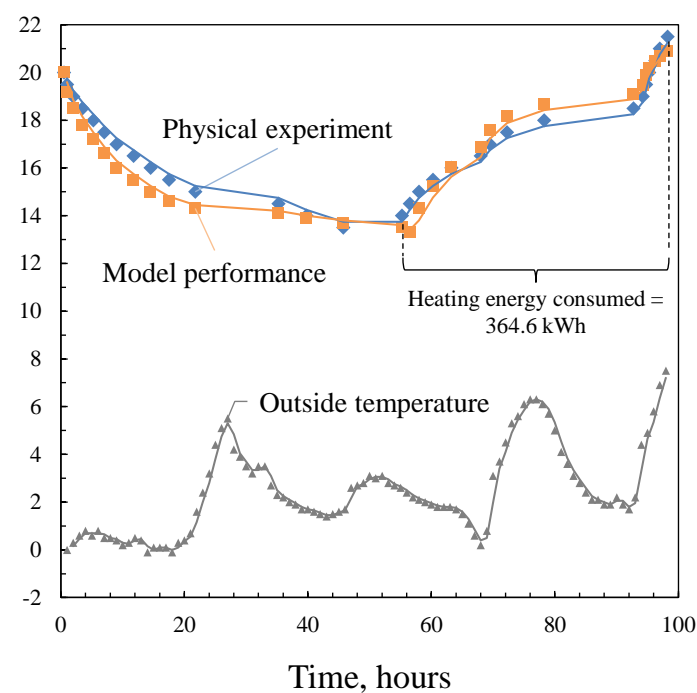

Fig. 12. Physical experiment data of room temperature and the corresponding model performance 


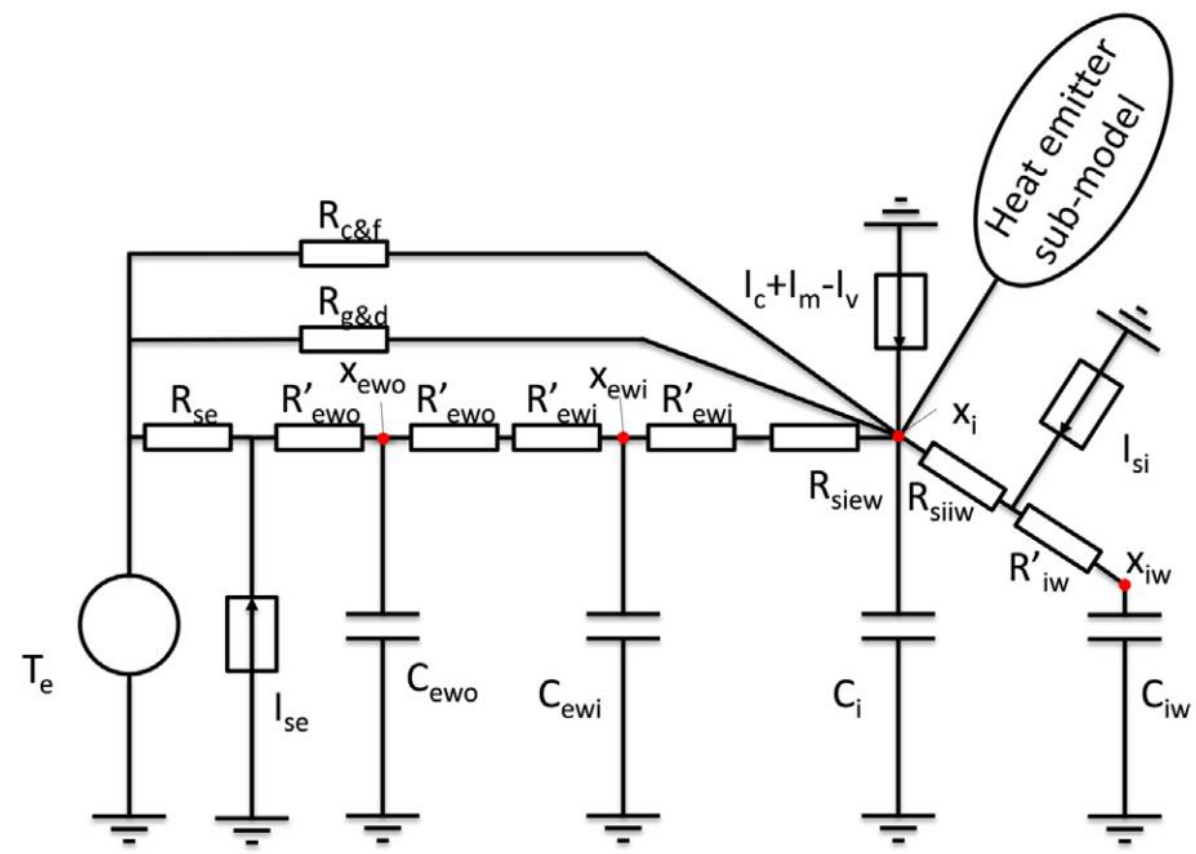

Fig. 13. The complex thermal network [15] used for comparison with the simplified model: $C_{\text {ewo }}, C_{\text {ewi }}$-thermal capacitance of the outer and inner portion of the external wall, respectively; $C_{\mathrm{i}}, C_{\mathrm{iw}}$ — thermal capacitance of the inside zone of the building and the internal wall; $I_{\mathrm{c}} I_{\mathrm{m}}-$ cooking and metabolic heat gain; $I_{\mathrm{se}}, I_{\mathrm{si}}$ - solar gain on external and internal building elements; $I_{\mathrm{v}}$ - heat exchange through ventilation (with external environment); $R_{\mathrm{c} \& f}, R_{\mathrm{g} \& \mathrm{~d}}-$ combined thermal resistance of ceiling and floor, glazing and doors; $R_{\text {ewi }}, R_{\text {ewo }}^{\prime}$-half of the thermal resistance of the inner and outer portion of the external wall; $R_{\text {iw }}$ half of the thermal resistance of the internal wall; $R_{\mathrm{se}}$ - external surface resistance; $R_{\text {siew }}, R_{\text {siiw }}$ internal surface thermal resistance, external and internal wall; $T_{\mathrm{e}}$ - external temperature evolution; $x_{\text {ewo }}, x_{\mathrm{ewi}}$ - temperature of the outer and inner portion of the external wall; $x_{\mathrm{i}}-$ temperature of indoor environment; $x_{\mathrm{iw}}-$ temperature of the internal wall.

\section{B. Comparison of the Simplified Model with an EnergyPlus calibrated model}

We compared the performance of the simplified model (Fig. 5) to a more complex thermal network model (Fig. 13) by running simulations on both models. The complex RC model is based on [15] with a few modifications.

The complex model presents one of the residential building archetypes (a mid-floor apartment) in Ireland initially developed in EnergyPlus simulation platform with a very high granularity of data [16]. Then, the reduced-order thermal network model (Fig. 13) was derived by calibration based on the detailed EnergyPlus archetype model output. Solar gains and ventilation losses were calculated based on weather data of one year with an hourly resolution.

The reduced-order RC model is necessary for modelling the aggregated electric load of heaters with an affordable computational effort to integrate it into power system models. This is the subject of our upcoming studies in modelling the large-scale impact of smart electric thermal storage.

Using the derived thermal network model, simulations were performed on it at the outside temperature of $0{ }^{\circ} \mathrm{C}$. Fig. 14 shows the indoor air temperature dynamics for a single day. By using the output of the complex EnergyPlus calibrated model, we estimated the parameters for the corresponding simplified model (Fig. 5) and run simulations on it at the same outside temperature. As shown in Fig. 14, the simplified model was able to replicate the temperature dynamics of the complex model with a high accuracy. This implies that the simplified model should also be able to accurately model the heating demand characteristics of the building.

\section{Temperature, ${ }^{\circ} \mathrm{C}$}

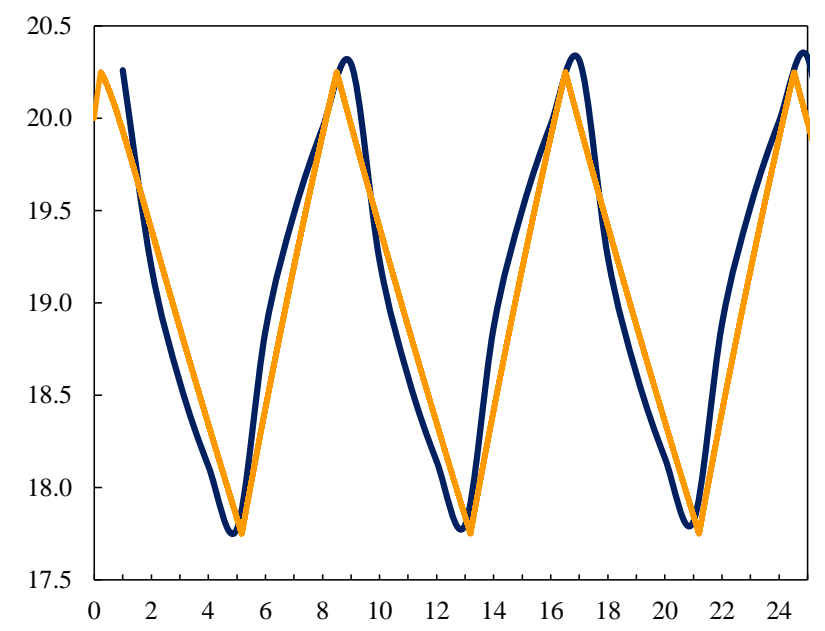

Time, hours

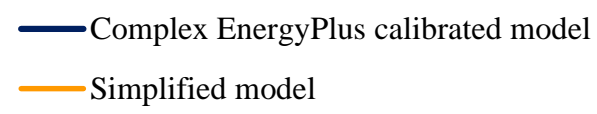

Fig. 14. Comparison of room temperature as per the complex EnergyPlus calibrated model and the simplified model 


\section{CONCLUSIONS}

The simplified thermal network model was able to capture the thermal dynamics of the building by using only the measured inside and outside temperature. The simplified model was obtained through inverse black-box modelling and exhibited a high accuracy as compared to performance of two more complex models in virtual experiments and an existing building in a physical experiment. It will serve as the first stage of modelling aggregate residential heat demand having a small setup cost and little computational effort in comparison to other approaches of building thermal modelling.

This research will be continued by employing physical experiments in 50 buildings in Latvia and obtaining temperature measurements of these buildings over an extended period of time. Using the experimental data, we will derive thermal characteristics for various types of buildings. Thus, we will be able to calculate the heating demand of representative individual buildings and extrapolate it to a national scale to further assess the impact of a large amount of smart electric thermal storage appliances on the power system.

\section{REFERENCES}

[1] A. McDonald, "Thermal Storage Device," US 2015/0055941 (A1), 2015 .

[2] J.-M. Durand, M. J. Duarte, and P. Clerens, "Joint EASE/EERA recommendations for a European Energy Storage Technology Development Roadmap towards 2030,” 2013.

[3] J. Raadschelders, F. Sikkema, and B. in 't Groen, "Potential for Smart Electric Thermal Storage. Contributing to a low carbon energy system," Arnhem, 2013.

[4] V. S. K. V. Harish and A. Kumar, "A review on modeling and simulation of building energy systems," Renew. Sustain. Energy Rev., vol. 56, pp. 1272-1292, Apr. 2016.

[5] A. Foucquier, S. Robert, F. Suard, L. Stéphan, and A. Jay, "State of the art in building modelling and energy performances prediction: A review," Renew. Sustain. Energy Rev., vol. 23, pp. 272-288, Jul. 2013.

[6] G. Reynders, J. Diriken, and D. Saelens, "Quality of grey-box models and identified parameters as function of the accuracy of input and observation signals," Energy Build., vol. 82, pp. 263-274, Oct. 2014.

[7] J. L. M. Hensen and R. Lamberts, Building Performance Simulation for Design and Operation. Spon Press, 2011.

[8] A. Rabl, "Parameter Estimation in Buildings: Methods for Dynamic Analysis of Measured Energy Use," J. Sol. Energy Eng., vol. 110, no. 1, pp. 52-66, 1988.
[9] J. V. Beck and K. J. Arnold, Parameter Estimation in Engineering and Science. John Wiley \& Sons, 1979.

[10] S. Ihara and F. C. Schweppe, "Physically based modeling of cold load pickup," IEEE Trans. Power Appar. Syst., vol. PAS-100, no. 9, pp. 4142-4150, 1981

[11] G. Fraisse, C. Viardot, O. Lafabrie, and G. Achard, "Development of a simplified and accurate building model based on electrical analogy," Energy Build., vol. 34, no. 10, pp. 1017-1031, Nov. 2002.

[12] C. P. Underwood, "An improved lumped parameter method for building thermal modelling," Energy Build., vol. 79, pp. 191-201, Aug. 2014.

[13] A. P. Ramallo-González, M. E. Eames, and D. A. Coley, "Lumped parameter models for building thermal modelling: An analytic approach to simplifying complex multi-layered constructions," Energy Build., vol. 60, pp. 174-184, May 2013

[14] M. M. Gouda, S. Danaher, and C. P. Underwood, "Building thermal model reduction using nonlinear constrained optimization," Build. Environ., vol. 37, no. 12, pp. 1255-1265, Dec. 2002.

[15] N. Good, L. Zhang, A. Navarro-Espinosa, and P. Mancarella, "High resolution modelling of multi-energy domestic demand profiles," Appl. Energy, vol. 137, pp. 193-210, 2015.

[16] O. Neu, B. Sherlock, S. Oxizidis, D. Flynn, and D. Finn, "Developing building archetypes for electrical load shifting assessment: Analysis of Irish residential stock," in CIBSE ASHRAE Technical Symposium, 2014, pp. 1-19.

Zane Broka received her Master's degree in Power Engineering from Riga Technical University in 2014. Currently she is a 3 rd year $\mathrm{PhD}$ Researcher at the Institute of Power Engineering of RTU. Her major field of study is power system optimisation. Research interests also include terminology development and standardisation.

Jevgenijs Kozadajevs holds a PhD in Power Engineering from Riga Technical University since 2016. Currently he is a Resarcher at the Institute of Power Engineering of RTU. His main research fields are power system relaying, control and automation.

Antans Sauhats received Dipl.Eng., Cand.Techn.Sc. and Dr.Hab.Sc.Eng. degrees from Riga Technical University (former Riga Polytechnical Institute) in 1970, 1976 and 1991 respectively. Since 1991, he is Professor of Electric Power Systems and since 1996, he is Director of the Institute of Power Engineering of RTU.

Donal Finn ( $\mathrm{PhD}$, Associate Professor) works at the School of Mechanical and Materials Engineering, as well as being a member of the Energy Institute, University College Dublin. His research interests include: energy systems integration, demand side management, demand response, building energy simulation, heat pump and refrigeration systems.

Will Turner holds a $\mathrm{PhD}$ in Mechanical Engineering from the University of Reading since 2010. Currently Will is a Senior Researcher in the UCD Energy Institute, Dublin. His main area of research is building energy simulation. 